Revista de Negócios_ISSN 1980.4431_vol. 18, n.4, p.55_74, 2013_DOI:10.7867/1980-

431.2013v18n4p55_74

\title{
Estratégias de internacionalização e marca top of mind: o caso Sagatiba
}

\section{Internationalization strategies and top of mind brand: the Sagatiba case}

Francisco Américo Cassano

Universidade Mackenzie - Brasil

famcassano@uol.com.br

\author{
Abrão Caro \\ Universidade Mackenzie - Brasil \\ abraocaro@yahoo.com.br \\ Carlos Eduardo G. Saraiva Jr. \\ Universidade Mackenzie - Brasil \\ carlossaraiva@gmail.com \\ Livia Rodrigues Silva \\ Universidade Mackenzie - Brasil \\ liviasilva@gmail.com \\ Rafael Martins Prado Oliveira \\ Universidade Mackenzie - Brasil \\ rafaprado@yahoo.com.br \\ Marina Ramos Almeida \\ Universidade Mackenzie - Brasil \\ mralmeida@yahoo.com.br
}

Recebido em 17 de janeiro de 2013. Alterado em 17 de maio de 2013. Aprovado em 17 de junho de 2013.

Editor Responsável: Edson Roberto Scharf, Dr.

Processo de avaliação por double blind review

\section{Resumo}

O advento da globalização e a expansão internacional das empresas tornaram frequente a ação para desenvolver e promover marcas fortes nos mercados globais, para fazer seus produtos ou serviços conhecidos pelos clientes mundialmente. Com a competição entre empresas internacionalmente e o aumento das ações de marketing de produtos e serviços sobre os clientes ao redor do globo, surgiram estudos que buscaram aferir a retenção da marca de um produto ou serviço entre os clientes. Nesse contexto, surge a pesquisa top of mind, do 
tipo espontâneo e na qual os consumidores, questionados sobre qual a marca do melhor produto ou serviço de uma determinada área, concedem o nome da marca que mais lhe agradam. Apesar das pesquisas top of mind poderem representar uma importante ferramenta para orientar estratégias corporativas, uma vez que demonstram o posicionamento dos produtos e serviços da empresa frente à opinião dos consumidores, os diversos estudos acerca da elaboração de estratégias empresariais não apresentam considerações a respeito da construção de marcas top of mind através da internacionalização dos negócios. Assim, o objetivo geral do estudo foi descrever como a estratégia de internacionalização de uma empresa pode auxiliá-la para firmar sua(s) marca(s) como top of mind. Para tal, utilizou-se o método do estudo de caso com a companhia Sagatiba, empresa nacional fabricante de cachaça e conhecida pela sua atuação no mercado europeu ocidental. Os resultados obtidos permitiram observar-se que, principalmente, os consumidores europeus ocidentais: dificilmente compram uma marca sem nunca ter ouvido falar dela; não têm preferência por produtos vendidos em pontos de alto padrão; não têm preferência por produtos de países exóticos; marcas top of mind nem sempre são a primeira opção no processo de compra; não estão dispostos a pagar mais simplesmente pelo produto ser de uma marca famosa; não têm problemas em comprar novas marcas estrangeiras. .

Palavras-chave: estratégia corporativa, internacionalização de empresas, consumidores europeus ocidentais, marca top of mind, Sagatiba.

\footnotetext{
Abstract

The advent of globalization and the international expansion of companies made frequent the action to develop and promote strong brands in global markets, in order to make their products or services known by customers worldwide. With the international competition between companies and the increasing marketing activities of products and services for customers around the globe, studies that sought to measure the retention of the brand of a product or service among customers emerged. In this context, the top of mind research emerges, at the spontaneous type in which consumers questioned about what is the brand of the best product or service in a particular area, give the name of the brand that suits them best. Although the top of mind research can represent an important tool to guide corporate strategies, since it demonstrate the positioning of the company's products and services to consumer opinion, the several studies about the development of business strategies do not present any consideration regarding the construction of top of mind brands through the internationalization of business. Thus,
}

the overall objective of the study was to describe how the internationalization strategy of a company can help it to secure its brand(s) as top of mind. To this end, the method of the case study of a Brazilian company, manufacturer of Sagatiba cachaça, and known for its activities in the Western European market, was used. The results obtained have noted that, mainly Western European consumers: hardly buy a brand which they have never heard about; do not have a preference for products sold at points of high standard; do not have a preference for exotic countries products; top of mind brands are not always the first option in the purchasing process; are not willing to pay more only because the product is of a famous brand; have no problems with buying new foreign brands.

Keywords: corporative strategies, enterprises internationalization, western european consumers, top of mind brand, Sagatiba.

\section{Introdução}

O advento da globalização e a
conjunta expansão internacional das empresas tornaram frequente a ação das companhias em desenvolver e promover marcas fortes nos mercados globais, com o objetivo de fazer seus produtos ou serviços conhecidos pelos clientes mundialmente.

Com o acréscimo da competição internacional entre as empresas e $\mathrm{o}$ aumento das ações de marketing de produtos e serviços sobre os clientes espalhados ao redor do globo, surgiram estudos elaborados por institutos de pesquisa que buscaram auferir a retenção da marca de um produto ou serviço entre os clientes.

Nesse contexto, surge a pesquisa top of mind, uma pesquisa espontânea em que os consumidores, questionados pelo entrevistador sobre qual a marca do melhor produto ou serviço de uma determinada categoria, respondem o nome da primeira marca que lembram.

Apesar das pesquisas top of mind poderem representar uma importante ferramenta para orientar as estratégias corporativas, uma vez que demonstram o posicionamento dos produtos e serviços da empresa frente à opinião dos consumidores, os diversos estudos acerca da elaboração de estratégias empresariais não 
Francisco Américo Cassano

Carlos Eduardo G. Saraiva Jr.

Rafael Martins Prado Oliveira

apresentam considerações a respeito da construção de marcas top of mind através da internacionalização dos negócios (MINTZBERG, 2006; JOHNSON et al, 2007; HITT et al, 2008; GHEMAWAT, 2008; ANSOFF; MCDONELL, 2009). Dessa forma, foi proposto o seguinte problema de pesquisa: como as estratégias de internacionalização influenciam na evolução de uma marca para o nível top of mind?

Adicionalmente, o objetivo geral do estudo foi descrever como a estratégia de internacionalização de uma empresa pode auxiliá-la para firmar sua(s) marca(s) como top of mind. Para tal, foi utilizado o método do estudo de caso com a companhia Sagatiba, empresa nacional fabricante de cachaça e conhecida pela sua atuação no mercado europeu ocidental, combinado com questionário fechado dirigido à determinada amostra de consumidores europeus.

Justifica-se esse estudo pela sua contribuição acerca da obtenção de marcas top of mind como diferencial competitivo no acirrado mercado global, pelo auxílio à elaboração de estratégias de internacionalização que contemplem a construção de marcas de sucesso nos mercados de interesse, além de representar uma oportunidade para que os administradores possam fazer uso das pesquisas top of mind como instrumento de verificação da eficácia da estratégia corporativa.

Como objetivos específicos, o estudo apresentou as principais razões pelas quais as empresas expandem sua atuação para o comércio internacional; identificou os principais fatores que determinam o sucesso de uma estratégia de internacionalização; apontou os principais tipos de internacionalização adotada no meio corporativo; avaliou as vantagens e desvantagens dos principais modos de entrada em mercados globais; verificou a colaboração de marcas top of mind para a criação de vantagens competitivas; analisou a influência das estratégias de interna-
Abrão Caro

Livia Rodrigues Silva

Marina Ramos Almeida

cionalização para obtenção de marcas top of mind.

\section{Referencial teórico}

A evolução de uma marca para o nível top of mind em um mercado não doméstico, ou seja, fora do país de origem da empresa, depende da forma como a empresa disponibiliza e promove o produto ou serviço aos clientes presentes no mercado internacional. Assim sendo, o sucesso de uma empresa em tornar a marca de seu produto ou serviço top of mind guarda uma relação de dependência com a estratégia de internacionalização que será adotada (AAKER; JOACHIMSTHALER, 2007).

\subsection{Internacionalização de empresas}

Internacionalização de empresas se refere ao processo que as organizações tomam para disponibilizar e comercializar seus produtos ou serviços para mercados além das fronteiras nacionais. Assim sendo, pode-se entender a internacionalização de empresas como sendo a maneira pela qual as companhias atuam nos mercados globais, vendendo seus produtos e ofertando serviços mundialmente (NUMMELA; SAARENKETO; PUUMALAINEN, 2004).

A estratégia de internacionalização da companhia é independente em relação às percepções que um cliente atribui a uma marca, pois, para que uma estratégia seja formulada não é preciso que a empresa possua uma marca top of mind (JOHNSON; SCHOLES; WHITTINGTON, 2007).

Ghemawat (2008), definiu internacionalização como um processo de concepção do planejamento estratégico relacionado com a sua respectiva implementação, a fim de que uma empresa tenha condições de atuar em diferentes países.

Portanto - contrapondo-se aos comceitos apresentados de internacionalização 
de empresas - é possível se afirmar que a internacionalização é a inserção de suas atividades em mercados além de suas fronteiras nacionais, atrelada a uma estratégia sobre como a companhia realizará essa imersão no comércio mundial.

Com o advento da globalização e a intensificação do comércio internacional, cada vez mais as empresas expandiram suas atividades além das fronteiras nacionais. A decisão pela internacionalização pode se embasar em diversas razões, porém, o principal fator para que as empresas se internacionalizem é a possibilidade de explorar oportunidades de negócios fora do mercado doméstico (ANSOFF; MCDONELL, 2009).

Porter e Montgomery (1998) afirmaram que é a concorrência internacional um dos fatores determinantes para que as empresas busquem uma atuação global. Para evitar o comprometimento dos negócios no mercado doméstico perante a ação da concorrência global, as empresas buscam se internacionalizar, adquirindo competitividade ao reposicionar seus negócios além das fronteiras nacionais.

Corroborou Mintzberg (2006), com a visão de Porter e Montgomery, a respeito da internacionalização como ação paliativa contra a concorrência global e acrescentou que, além de possibilitar um melhor posicionamento da empresa perante os competidores domésticos e globais, TAMbém possibilita que a empresa tenha acesso a novas fontes de recursos presentes nos mercados mundiais. $\mathrm{O}$ contato com mercados de características diferentes do mercado doméstico permite que as empresas ampliem seu leque de obtenção de informações e de recursos e, com isso, estimulem e orientem seus negócios e o desenvolvimento de produtos com uma gama maior de informações.

Lorga (2003), por outro lado, apresentou como determinantes para a internacionalização da empresa a ideia de balanço entre oportunidades que podem ser auferidas pela organização em uma ação global e os riscos associados ao processo. A escolha pela internacionalização é dada pelos estímulos oriundos do mercado internacional, e, em face de tais estímulos, as empresas posicionar-se-ão proativamente, buscando expandir suas atividades globais quando as condições ambientais dos mercados em potencial se demonstrarem atrativas ou reativamente, evitando o comércio internacional em contextos de altos riscos envolvidos.

Ghemawat (2007), entretanto, comsidera que a internacionalização das empresas tem um caráter mais financista, ligado à necessidade de prover retornos acima da média aos seus acionistas. A ação internacional corporativa pode propiciar ganhos para a empresa, a saber: elevação na participação de mercado; maiores retornos sobre investimentos em unidades fabris fora do país de origem; economias de escala; aumento da pesquisa e desenvolvimento; aprendizagem sobre a dinâmica dos negócios globais; maior acesso a informações. Esse conjunto de possíveis ganhos, que uma empresa pode auferir em sua internacionalização, propiciará um aumento da rentabilidade de suas operações. É através dessa possibilidade de retornos, acima da média, que as empresas buscam a internacionalização de suas atividades.

Johnson, Scholes e Whittington (2007) reafirmaram as ideias sobre a internacionalização como ação contra a concorrência, exposta por Porter e Montgomery (1998). Porém, acrescentaram que, para muitas empresas, a internacionalização surge como um efeito dominó, principalmente aquelas ligadas à cadeia de fornecedores, visto que com a internacionalização de seus clientes, tais empresas também iniciam processo de expansão global para acompanhá-los e explorar a oportunidade de se tornarem fornecedores de outras corporações internacionais. Também afirmaram que as empresas, ao expandirem seus mercados internacionalmente, evitam as limitações do seu próprio mercado interno. 
Francisco Américo Cassano

Carlos Eduardo G. Saraiva Jr.

Rafael Martins Prado Oliveira

Ghemawat (2008) apoiou a visão de Johnson, Scholes e Whittington (2007) sobre a expansão internacional como forma de ultrapassar as barreiras intrínsecas do mercado nacional e desfrutar de melhor ambiente institucional de outros mercados. Ressaltou que os motivos da internacionalização de empresas frequentemente estão relacionados com questões ambientais do mercado doméstico e não apenas com as características dos mercados globais.

Através do Quadro 1 verifica-se que as razões para a internacionalização de empresas brasileiras, apontadas por Almeida (2007), se adéquam com os principais fatores identificados pelos autores já citados e relacionados com os motivos que levam uma empresa a se
Abrão Caro

Livia Rodrigues Silva

Marina Ramos Almeida

inserir no comércio internacional.

Verifica-se também que uma das razões para a internacionalização de empresas brasileiras é a busca por eficiência em ganhos de arbitragem, ou seja, ao adentrar em outros mercados, principalmente os de países desenvolvidos, as empresas gozam de melhor arcabouço jurídico para condução dos negócios, diferentemente do que ocorre no Brasil, onde notadamente as empresas enfrentam dificuldades com a lentidão do poder judiciário e da burocracia do poder executivo, o que é compatível com as observações de Johnson, Scholes e Whittington (2007) e Ghemawat (2008) acerca da internacionalização como maneira de se desvencilhar das obsolescências do mercado de origem.

Quadro 1. Motivos de internacionalização para empresas brasileiras

\begin{tabular}{|c|l|}
\hline \multirow{2}{*}{ Expansão de mercado } & - Maior capacidade de resposta aos clientes internacionais \\
& - Fortalecimento da posição competitiva \\
& - Diversificação do portfólio geográfico e redução de riscos \\
\hline \multirow{3}{*}{ Melhoria da eficiência } & - Economias de escala e de escopo \\
& - Acesso a recursos a custos inferiores \\
& - Ganhos de arbitragem \\
\hline \multirow{3}{*}{ Aprendizagem } & - Acumulação de conhecimento e desenvolvimento das competências \\
& empresariais existentes \\
& - Alavancagem de competências empresariais a novos produtos e \\
& segmentos \\
& - Desenvolvimento e aquisição de novas competências empresariais \\
\hline
\end{tabular}

Fonte: Almeida, 2007, p. 83.

\subsection{Estratégias de internacionalização}

Conforme já exposto, os motivos que levam as empresas a se internacionalizarem envolvem um conjunto de razões que permitem o desencadeamento desse processo. Entretanto, é necessária a existência de uma estratégia para que tal movimento corporativo seja devidamente conduzido.

A palavra estratégia tem sido utilizada desde as primeiras civilizações. Segundo Houaiss (2006), etimologicamente, strategos (em grego) representava o cargo de um comandante de uma armada, uma espécie de ministro da guerra, responsável pelo planejamento militar da Grécia Antiga. Assim sendo, desde a
Antiguidade, a ideia de estratégia estava ligada ao planejamento meticuloso em prol da conquista de importantes vitórias. $\mathrm{Na}$ atualidade, o conceito de estratégia ganhou novos contornos, visto que a palavra foi incorporada ao contexto da administração de negócios.

É nesse contexto corporativo que Ansoff e McDonell (2009) afirmaram que estratégia é um conjunto de diretrizes elaboradas pela empresa para orientar o comportamento da organização em prol dos objetivos e metas traçados.

Henderson (1998) já havia afirmado que estratégia é a busca de um plano de ação para desenvolver uma vantagem competitiva para a empresa se 
destacar em relação aos seus concorrentes.

Portanto, para Ansoff e McDonell (2009) e para Henderson (1998), a estratégia é marcada pela tomada de decisões e ações que uma empresa realiza para atingir objetivos, notadamente desenvolver, preservar e adequar vantagens competitivas.

Mintzberg (2006) também registrou que estratégia é o padrão que uma empresa adota para a execução de suas atividades e para orientação dos negócios, desde o estabelecimento de políticas internas até o modo de relacionamento com os clientes.

Johnson, Scholes e Whittington (2007) ligaram uma estratégia de longo prazo à obtenção de vantagens competitivas em mercados com frequentes mudanças e ao modo como a empresa mobilizará e administrará seus recursos e competências em prol do objetivo de atender seus stakeholders (possíveis interessados nos negócios da companhia como acionistas, clientes, governo, sociedade, entre outros).

É sob essa questão fundamental da sustentabilidade corporativa, de assegurar a perpetuidade da empresa no decorrer do tempo, que a estratégia se faz presente nas organizações atuais, representando um alicerce no qual a empresa se apóia para cumprir seus objetivos e metas e, consequentemente, satisfazer as expectativas dos stakeholders (JOHNSON; SCHOLES; WHITTINGTON, 2007).

Verificada essa necessidade da formulação de uma estratégia para orientar a expansão dos negócios internacionalmente, torna-se necessário citar os principais fatores que devem ser considerados para a formulação de uma estratégia de internacionalização.

Ansoff e McDonell (2009) observaram que, ao identificar oportunidades de negócios nos mercados não domésticos, as empresas acabam realizando um mapeamento de tais mercados. Nesse contexto, criaram a ideia de AEN (área estratégica de negócio) para orientar a formulação de uma estratégia empresarial.
Uma AEN representa um mercado com características próximas, desde aspectos culturais e de comportamento do consumidor até critérios geográficos como localização e clima. Dessa maneira, as empresas precisam observar as especificidades ambientais da AEN que se pretende explorar, considerando as características dos clientes, do produto ou serviço, da infraestrutura, dos aspectos políticos e econômicos (ANSOFF; MCDONELL, 2009).

Ao adentrar no comércio internacional, as organizações esperam encontrar novos concorrentes e uma dinâmica distinta de competição à qual estão acostumadas. Outros fatores distintos provávelmente se farão presentes em novos mercados, como nível de desenvolvimento econômico, tamanho do mercado para os produtos ou serviços da empresa, grau de saturação do mercado, entre outros (PORTER; MONTGOMERY, 1998).

Os aspectos culturais também terão impactos relevantes na formulação de uma estratégia, pois o comportamento do consumidor em mercados globais poderá se distinguir dos clientes que a empresa já atende. Gostos de consumo, hábitos de compras, nível de renda e instrução, idioma, entre outros fatores, podem ser determinantes para o sucesso do negócio em um mercado global (LORGA, 2003).

É necessário que as empresas observem fatores políticos e de regulamentação dos mercados nos quais pretendem atuar. $\mathrm{O}$ ambiente político-legal pode ser bastante diverso do que a empresa está acostumada em seu país de origem, fazendo-se necessário compreender-se adequadamente esse cenário antes de uma empreitada internacional (ALMEIDA, 2007).

Para que se possa realizar a devida análise sobre o conjunto de fatores que compõem as condições e tendências ambientais, Johnson, Scholes e Whittington (2007), considerando as observações de Porter e Montgomery (1998) sobre a necessidade de uma correta avaliação das 
Francisco Américo Cassano

Carlos Eduardo G. Saraiva Jr.

Rafael Martins Prado Oliveira

características ambientais, utilizaram o diagrama de análise PESTEL, formulado sob a análise das dimensões políticas, econômicas, sociais, tecnológicas, ambientais e legais que compõem o ambiente externo da organização.

Com a estrutura PESTEL, surgem diversas características ambientais que as empresas devem observar sobre os mercados globais de interesse. Diferenças entre os aspectos políticos, os fatores econômicos e socioculturais, o ambiente legal, o nível de envolvimento com tecnologia e questões de trato com o meio ambiente são determinantes para o sucesso de uma corporação estrangeira em um novo mercado. As variações e combinações dos fatores externos à organização impactam significativamente o sucesso das estratégias corporativas, sobretudo no ambiente competitivo global (JOHNSON; SCHOLES; WHITTINGTON, 2007).

Ghemawat (2008), complementarmente à estrutura PESTEL de Johnson, Scholes e Whittington, propôs a utilização de um modelo analítico que trata das diferenças entre mercados atrelados à ideia de distância, não apenas ao conceito de distância geográfica, mas também ligado à ideia de distância entre dimensões de análise, pois, eventualmente, países próximos geograficamente podem estar muito distantes em características ambientais, assim como países longínquos podem apresentar semelhanças com o mercado doméstico.

Através da análise de dimensões Culturais, Administrativo-Políticas, Geográficas e Econômicas, surgiu a estrutura CAGE, como ferramenta de apoio para identificar, não apenas os mercados que apresentam diferenças centrais individualmente, mas também para viabilizar a análise de características ambientais por pares de países, ou seja, via modelo comparativo. A estrutura CAGE revela como é possível notar a distância entre países em função das diferenças ambientais entre os mercados. Desse modo,
Abrão Caro

Livia Rodrigues Silva

Marina Ramos Almeida

através da análise das dimensões apresentadas no modelo CAGE, as diferenças entre mercados se tornam visíveis, possibilitando que a empresa entenda as especificidades dos mercados que pretende atuar e oriente sua estratégia contemplando as características locais (GHEMAWAT, 2008).

Uma vez analisados os fatores ambientais dos mercados de interesse globais, as organizações devem despender esforços na adequada observação acerca do posicionamento da concorrência. A estratégia empresarial deve essencialmente se munir contra a ação da concorrência e buscar posicionar a empresa em uma posição confortável em relação aos seus competidores (PORTER, 1979).

É importante compreender-se a questão da concorrência, não apenas como sendo um fator isolado na formulação da estratégia corporativa, mas interpretando o comportamento competitivo em um sistema no qual competidores, clientes, dinheiro, pessoas e recursos são interativos em todos os momentos (HENDERSON, 1998).

Observados os critérios da análise ambiental e da ação da concorrência, outro importante ponto para formulação de uma estratégia de internacionalização é a mensuração dos riscos envolvidos na expansão global. Muitos dos riscos envolvidos podem ser auferidos pela análise dos critérios ambientais através das estruturas até agora apresentadas: PESTEL (JOHNSON; SCHOLES; WHITTINGTON, 2007) e CAGE (GHEMAWAT, 2008). Entretanto, é improvável a mitigação completa do risco empresarial, sobretudo, em um processo de internacionalização. Dessa maneira, uma conhecida ferramenta da administração de empresas propõe a identificação dos riscos e ameaças inerentes à atividade corporativa: a análise SWOT, acrônimo para as palavras em inglês Strengths, Weaknesses, Opportunities e Threats (GHEMAWAT, 2007).

A análise SWOT surgiu na década 
de 1960 através de discussões em salas de aula de administração de empresas acerca dos riscos e oportunidades da atividade empresarial. $\mathrm{O}$ balanço entre riscos e oportunidades é que move a tomada de decisões de uma empresa sobre o desenvolvimento dos seus negócios (LORGA, 2003). Desse modo, a análise SWOT representou importante avanço sobre a mensuração de riscos para formulação de estratégias empresariais (GHEMAWAT, 2007).

Elencada a importância da análise das características ambientais, da ação da concorrência e da identificação dos riscos envolvidos em um processo de internacionalização, é preciso observar os aspectos internos da corporação para que a elaboração da estratégia possa ser feita de maneira a considerar também as características da própria empresa.

A expansão internacional consiste em globalizar uma estratégia internacional, integrando as ações de diversos países em uma administração que viabilize o alcance dos objetivos traçados no planejamento estratégico (MINTZBERG, 2006).

Dessa maneira, é preciso que a estratégia de internacionalização também considere as alterações corporativas que se farão necessárias para tornar a organização apta a exercer suas atividades internacionalmente (ALMEIDA, 2007).

Almeida (2007), em sua obra sobre internacionalização de empresas brasileiras, também afirmou que é facilmente verificável casos de empresas nacionais que não se prepararam e planejaram internamente para uma expansão internacional, tendo iniciado sem planejamento prévio e, consequentemente, sem uma correta ação estratégica.

Devido às perdas de uma ação internacional sem o devido preparo interno, as organizações passaram a realizar um processo de autoanálise com a utilização de uma estrutura flexível que lhes possibilitasse adaptarem-se às demandas de gerenciamento de atividades do comércio internacional. Além dos aspectos de planejamento operacional, as companhias começaram a observar critérios como governança corporativa, mercado de capitais, perspectiva multicultural, dimensão global (produtos, serviços, suprimento e marca), responsabilidade social, tecnologia da informação, gestão de risco (negócio, câmbio, mercados) e outros aspectos de mudança interna que visasse uma interação mais adequada com o comércio internacional (ALMEIDA, 2007).

Além da adequação de aspectos internos da organização com relação aos processos, práticas e políticas, faz-se necessário uma adequada observação com relação aos aspectos culturais para uma atuação internacional, visto que cultura é, simultaneamente, aspecto interno da empresa - cultura organizacional e nacional dos indivíduos que trabalham na corporação - e externo - ambiente cultural dos mercados globais. A cultura pode ser vista como resultado das influências que as normas e valores da sociedade exercem sobre as pessoas, um fenômeno inconsciente que define como os indivíduos observam o mundo ao seu redor, enxergam a si próprios e guiam o modo de se relacionar com as outras pessoas, a sociedade, a natureza e o universo (KOTLER, 2009).

Ainda segundo Kotler (2009) existem subculturas dentro de uma cultura central, que fornecem identificação e socialização mais específica aos seus membros. Os indivíduos que compõem uma subcultura, nitidamente, possuem preferências homogêneas sobre produtos e marcas em diversas áreas.

Johnson, Scholes e Whittington (2007), assim como Kotler (2009), apontaram a possível maximização de oportunidades de negócios na abordagem de subculturas, afirmando que pode ser necessário identificar quais são as subculturas (geralmente regionais) presentes em um mercado global.

Cabe às organizações que buscam a maximização da exploração de oportuni- 
Francisco Américo Cassano

Carlos Eduardo G. Saraiva Jr.

Rafael Martins Prado Oliveira

dades nos mercados globais, comercializar produtos e serviços em conformidade com os valores culturais centrais e subculturais dos mercados em que pretendem atuar sob o risco de, se não o fizer, arcar com prejuízos com relação à imagem de seus produtos e serviços e ao comprometimento do sucesso de sua atuação internacional (KOTLER, 2009).

Ghemawat (2008) comentou sobre a necessidade de se evitar extremos do localismo - visto os altos custos atrelados a um alto nível de customização de produtos e serviços, além da intensificação da complexidade de gerenciamento da empresa mundialmente - e a padronização total de produtos e serviços, que evidentemente, ignoraria importantes aspectos culturais. Desse confronto entre padronização e customização cultural, surgiu a ideia de variação como forma de adaptação às diferenças entre mercados.

Assim, a cultura impacta na estratégia de internacionalização de diversas formas, desde a análise ambiental, da identificação de oportunidades em subculturas, do embate entre customização e padronização até a própria cultura de origem da organização, que, em determinadas situações, poderá se revelar um instrumento de diferencial competitivo. Uma vez observados os principais fatores que contribuem para elaboração de uma assertiva estratégia de internacionalização, as empresas, usualmente, adotam determinados tipos de estratégias conhecidas no meio corporativo.

O modelo da Escola de Uppsala, inspirado por Johanson e Vahlne (1977), apontou três principais estágios de estratégias de internacionalização que as empresas adotam:

i. Inicialmente as empresas iniciam o contato com o exterior através de exportações;

ii. Conforme as atividades em países estrangeiros se acumulam, as empresas avançam para o estágio internacional. A passa-
Abrão Caro

Livia Rodrigues Silva

Marina Ramos Almeida

gem para o nível internacional é marcada pela descentralização progressiva das atividades globais, ocorrendo uma distribuição administrativa entre os países que a empresa atua;

iii. O passo na direção multinacional tem como característica a aquisição de responsabilidades estratégicas novas e vitais para a organização mundialmente, com o surgimento de uma administração central estratégica que oriente as relações da empresa com os diversos mercados globais.

Perlmutter (1969) já havia classificado as empresas multinacionais em: etnocêntricas, que consideram seus métodos e produtos no país de origem como superiores; policêntricos, que consideram cada subsidiária mais independente da matriz e com atuação mais voltada para o mercado local; geocêntricas, que possuem um estilo cosmopolita e integrativo.

Bartlett e Ghoshal (1992), utilizando o conceito de empresas geocêntricas definido por Perlmutter (1969), denominaram de empresas transnacionais que, para continuarem competitivas, reconheciam a necessidade de alcançar simultaneamente a eficiência global e a Receptividade nacional, além da capacidade de desenvolver e explorar o conhecimento em termos mundiais.

Johnson, Scholes e Whittington (2007) sugeriram uma intersecção entre os estudos de Johanson e Vahlne (1977) e de Bartlett e Ghoshal (1992), ao afirmarem que, geralmente, as empresas buscam uma evolução gradual com os mercados globais, em função da necessidade de aprendizagem via contato com os mercados, concomitantemente com a necessidade de proteger seus ativos a riscos que possam estar presentes no processo inicial de aporte no mercado estrangeiro.

À medida que a inserção internacional se intensifica, as empresas se vêem 
diante de uma dicotômica questão: o aumento do atendimento das especificidades locais ou a expansão global via padronização, conhecido como dilema global-local. Uma segunda questão estratégica, advinda da expansão global, relaciona-se com o grau em que ativos e capacidades produtivas estão concentradas em um número limitado de países ou descentralizados e distribuídos mundialmente. Sob a análise dessas duas questões estratégicas, as empresas optam por um modelo de internacionalização multidoméstico, com a busca pelo atendimento às necessidades dos consumidores locais ou por um modelo global, com alto nível de padronização, com ênfase nos ganhos de economia de escala e com uma estrutura mais rígida e centralizada administrativamente (JOHNSON; SCHOLES; WHITTINGTON, 2007).

Contudo, em detrimento da teoria de internacionalização gradual, têm se verificado casos de empresas que nasceram globais, ou seja, desde a fundação ou em poucos anos de existência iniciaram um modelo de internacionalização global. As chamadas Born globals (nascidas globais), enfatizam menos o acúmulo gradual de experiência internacional e priorizam a entrada rápida em mercados estrangeiros incipientes, onde agilmente conquistarão espaço entre os consumidores, visto que tais empresas estão geralmente ligadas a segmentos de mercados novos e aportam em mercados com pouca ou nenhuma concorrência (JOHNSON; SCHOLES; WHITTINGTON, 2007).

Sobre a expansão das empresas Born globals, Dib e Rocha (2008) apontaram como fatores determinantes no surgimento de tais empresas o tamanho do mercado do país de origem, sua localização, seu grau de abertura comercial e a existência de uma economia baseada em conhecimento.

$\mathrm{Na}$ prática, portanto, as empresas dificilmente se encaixarão em um modelo definido teoricamente para realizar sua expansão internacional. De acordo com as diretrizes existentes, as empresas buscarão uma forma de equilibrar competências internas com oportunidades externas ao formular sua própria estratégia de internacionalização (JOHNSON; SCHOLES; WHITTINGTON, 2007).

Uma vez decidido o tipo de estratégia de internacionalização que uma empresa confeccionará para sua inserção mundial, é necessário avaliar de que maneira a empresa aportará nos mercados de interesse, ou seja, quais serão os modos de entrada que a corporação utilizará para iniciar o contato com o comércio internacional.

Johanson e Vahlne (1977) também apontaram cinco modos de entrada em mercados globais: exportação de produtos; acordos de licenciamento; alianças estratégicas; aquisições; estabelecimento de novas subsidiárias totalmente próprias.

Próximo da proposta de Johanson e Vahlne (1977) sobre os modos de entrada no comércio internacional, Johnson, Scholes e Whittington (2007) apontaram quatro tipos de entrada: exportação; joint ventures (associações entre empresas com a finalidade específica de explorar oportunidades em conjunto, compartilhando recursos e informações) e alianças; licenciamento; investimento direto no exterior.

Para orientar a correta escolha dos modos de entrada, a empresa deverá observar os elementos analisados na elaboração da estratégia acerca das características externas e internas da organização e seguir o planejamento estratégico instituído para sua ação internacional (JOHNSON; SCHOLES; WHITTINGTON, 2007).

\subsection{Marca top of mind}

Apesar do comércio de produtos ser uma atividade praticada desde as primeiras civilizações, é apenas no século XX que ocorre a intensificação da importância das marcas como instrumento influenciador no processo de compra. Uma marca tem como objetivo sinalizar ao consumidor a origem do produto ou serviço, distinguindo-se de 
Francisco Américo Cassano

Carlos Eduardo G. Saraiva Jr.

Rafael Martins Prado Oliveira

competidores através de seus atributos (AAKER, 1998).

Segundo Kotler (2009), uma marca representa um nome, termo, signo, símbolo ou design, podendo também ser uma combinação desses elementos, para identificar um produto ou serviço e diferenciá-lo perante seus concorrentes.

É nesse panorama, de importância da construção de marcas fortes como força motriz de ganhos competitivos apontado por Aaker (1998), que surge a ideia de marca top of mind. $\mathrm{O}$ possível conhecimento de uma marca se dá em quatro estágios distintos: o nível mais baixo é o desconhecimento, que ocorre quando um indivíduo é consultado sobre uma marca e, mesmo através de elementos de estímulo utilizados pelo entrevistador, é incapaz de apontar qual é a marca em questão; o segundo nível, reconhecimento, é aquele onde o entrevistado ao ser posto em frente a diversas marcas e atributos de um determinado produto ou serviço, associa corretamente o nome da marca ao atributo; o terceiro estágio, lembrança, ocorre quando o entrevistado é consultado sobre uma determinada marca e sem estímulos do pesquisador, aponta a resposta correta; o nível mais elevado é o top of mind, no qual o entrevistado, espontaneamente, sem apoio de qualquer instrumento de estímulo, fornece o nome de uma marca (AAKER, 1998).

Notadamente, os níveis de conhecimento de uma marca elencados por Aaker (1998) - desconhecimento, reconhecimento, lembrança e top of mind guardam entre si uma relação hierárquica piramidal, ou seja, o desconhecimento da marca está presente na maioria dos produtos e serviços comercializados (base da pirâmide), enquanto que apenas uma pequena parcela das marcas é espontaneamente lembrada pelos consumidores (topo da pirâmide).

Face à crescente dinâmica dos negócios globais, com relação à criação de uma economia do conhecimento, cada vez
Abrão Caro

Livia Rodrigues Silva

Marina Ramos Almeida

mais se intensifica a importância dos ativos intangíveis para o alcance de diferenciais competitivos que conferirão sustentabilidade às atividades corporativas no longo prazo (STEWART, 2004).

Uma vez que o valor da marca não é captado pelas demonstrações financeiras de uma companhia, visto a utilização do modelo contábil comumente adotado, torna-se de difícil aferição o retorno competitivo e, conseqüentemente, financeiro, que os investimentos em um ativo intangível, como a marca, podem proporcionar (EDVINSSON; MALONE, 1998).

Baseado no exposto por Edvinsson e Malone (1998), com relação à difícil aferição do retorno que os investimentos em marca podem acarretar, Grayson e Hodges (2002) citaram em seu estudo uma elucidadora pesquisa realizada pela consultoria Interbrand em 1999. De acordo com essa pesquisa, cerca de 99,9\% do valor de mercado da Coca-Cola está atrelado à reputação e conhecimento da sua marca. Outras empresas também apareceram na pesquisa, como Kellog's (97\%), American Express (84 \%) e IBM (83\%), revelando o quão importante uma marca pode representar como ativo para as organizações.

Assim sendo, é perceptível a contribuição dos investimentos em marca para ganhos competitivos de longo prazo, podendo ser determinantes para o sucesso de um empreendimento (AAKER; JOACHIMSTHALER, 2007).

Aaker e Joachimsthaler (2007) também alertaram que uma visão meramente ligada ao curto prazo perceberá que os investimentos no composto de marketing (investimentos em propaganda, promoção de vendas, relações públicas, venda direta e marketing direto) são elevados e, em curto período de tempo, poderá até reduzir os lucros de uma empresa. Portanto, um posicionamento administrativo de curto prazo poderá malograr a obtenção de possíveis vantagens competitivas advindas 
da construção de marcas fortes no longo prazo, sobretudo as top of mind.

Ao buscar atingir marcas top of mind, as empresas devem observar a questão com relação à satisfação do cliente com o produto ou serviço por detrás da marca. Uma base ampla de clientes satisfeitos proporcionará uma imagem de marca bem-sucedida e aceita, promulgando uma percepção positiva da marca para clientes em potencial. A construção de marcas top of mind pode resultar não apenas no conhecimento e lembrança da marca pelos clientes, mas também obter um destaque tal no mercado que iniba a ação de marcas concorrentes (AAKER, 1998).

Com relação à estratégia de internacionalização, por serem as marcas top of mind reconhecidamente percebidas como líderes em seus mercados de atuação - não uma liderança meramente de participação de mercado (muitas marcas top of mind não possuem a maior fatia do mercado), mas uma liderança atrelada a aspectos de qualidade e confiança do produto ou serviço por parte dos consumidores - a busca por tornar as marcas de seus produtos top of mind nos mercados globais pode conferir a uma organização características de liderança que, possivelmente, converter-se-ão em ganhos de imagem para os produtos e serviços que carreguem a marca (AAKER; JOACHIMSTHALER, 2007).

As marcas também são uma forma de comunicação da empresa com os segmentos de mercado de interesse. As companhias procuram criar identidade de marca que propicie comunicação com os clientes-alvo de seus produtos ou serviços, transmitindo atributos e buscando fixar percepções, sobretudo emocionais e subjetivas, como forma de criar ligação entre a marca e o segmento de mercado desejado. Assim sendo, nos mercados globais consideravelmente distintos da dinâmica de negócios nacional, as empresas em fase de internacionalização buscam, através da marca, associar valores e atributos locais específicos, como forma de aproximar o produto ou serviço dos novos clientes globais. Entretanto, apesar de reforçar elementos específicos para cada mercado ou segmento, é importante que as empresas procurem manter identidade única de marca, que possa ser reconhecida e lembrada globalmente por mercados diversos (AAKER; JOACHIMSTHALER, 2007).

Uma forma de mensurar se a estratégia global de marca está obtendo responsividade local é através das pesquisas top of mind. Oferecidas por consultorias e institutos de pesquisa, o levantamento top of mind poderá verificar se os objetivos com relação a uma marca global estão sendo alcançados através da estratégia de internacionalização da companhia. Estudos sobre a notoriedade da marca assumem um importante papel para o desenvolvimento e orientação das estratégias corporativas, não apenas pela sua contribuição sobre o desempenho de uma marca específica frente aos clientes, mas também pelas informações captadas sobre o que os clientes observam e desejam encontrar em uma marca, revelando tendências e interesses do mercado, possibilitando que uma empresa oriente suas estratégias em prol da construção de marcas top of mind (PIRES; ARANTES; SILVA; KATO, 2006).

Nos últimos anos, foi perceptível o aumento das empresas que iniciaram a busca pela obtenção de uma marca global top of mind em seus segmentos de atuação. Além do uso das marcas top of mind como vantagem competitiva, essa atratividade também é resultado dos indeléveis ganhos de economia de escala que marcas globais proporcionam, uma vez que o gerenciamento de uma pequena carteira de marcas globais é menos dispendiosa do que a administração de diversas marcas locais, conjuntamente com o aumento de poder de negociação com fornecedores que supram marcas renomadas internacionalmente $\mathrm{e}$ pelo aumento da facilidade em lidar com intermediários locais, uma vez que marcas 
Francisco Américo Cassano

Carlos Eduardo G. Saraiva Jr.

Rafael Martins Prado Oliveira

globais, especialmente as top of mind, carregam alto grau de confiabilidade e reconhecimento de qualidade pelos consumidores (AAKER; JOACHIMSTHALER, 2007).

Portanto, ao empreenderem uma abordagem global de suas marcas, objetivando o nível top of mind, as companhias devem construir uma gestão global da marca, que delibere sobre o planejamento de comunicação de marketing da empresa mundialmente e componha a estratégia de internacionalização adotada, com vistas ao alcance de uma estrutura corporativa capaz de posicionar as marcas da empresa corretamente frente às percepções dos consumidores e responder, de forma eficaz, as tendências e mudanças mercadológicas e competitivas mundiais (AAKER; JOACHIMSTHALER, 2007).

\section{Procedimentos Metodológicos}

Uma vez que o objetivo geral do estudo foi apontar como a estratégia de internacionalização auxilia uma empresa em firmar sua(s) marca(s) como top of mind, a pesquisa utilizou o método qualitativo, visto que os principais aspectos da pesquisa se fundamentam na escolha de teorias e métodos corretos e oportunos, na identificação e na análise de diferentes pontos de vista, nas reflexões dos pesquisadores sobre suas pesquisas como parte integrante na criação de conhecimento e nas diferentes vertentes de métodos.

O tipo de pesquisa adotado foi o descritivo, uma vez que os estudos dêscritivos são adequados para se observar, registrar, analisar e correlacionar fatos ou fenômenos, buscando estabelecer uma relação entre as variáveis envolvidas.

Dessa forma, o método qualitativo do tipo descritivo foi utilizado com a finalidade de estudar a influência das estratégias de internacionalização para obtenção de uma marca top of mind e testar
Abrão Caro

Livia Rodrigues Silva

Marina Ramos Almeida

a hipótese de que, possivelmente, existe uma influência do modo como uma empresa atua globalmente e a percepção, e consequente sucesso, de uma marca no exterior.

A pesquisa foi realizada no ano de 2009 e a amostra do estudo foi constituída por dois grupos distintos de entrevistados. O primeiro grupo foi composto por consumidores europeus, localizados na Alemanha e no Reino Unido. O segundo grupo foi composto pela empresa nacional do setor de cachaça Sagatiba, conhecida pela sua atuação internacional, e na qual se baseia o estudo de caso deste artigo.

Fundada em 2004, por um empresário brasileiro na cidade de Patrocínio Paulista - SP, a empresa Sagatiba Brasil S/A foi a primeira marca de cachaça a se estabelecer fora do Brasil. Desde 2010 a Sagatiba se uniu ao Grupo Campari, a fim de ampliar a sua participação no mercado internacional e contando para isso com a estrutura mercadológica que o novo parceiro possui há longo tempo (SAGATIBA, 2013).

O grupo de consumidores foi delineado para compor a amostra devido à proximidade com os mercados de interesse da empresa objeto do estudo (Sagatiba) somado à viabilidade de se contatar indivíduos para responder o questionário em tais países. Os nomes dos entrevistados foram mantidos em sigilo, visto à necessidade de se assegurar que as respostas fossem isentas de qualquer tipo de estímulo negativo resultante da publicação de seus nomes.

$\mathrm{Na}$ Sagatiba foram entrevistados três funcionários ligados à área gerencial da companhia. Os nomes dos entrevistados também foram preservados em sigilo, bem como qualquer informação de cunho confidencial da empresa obtida na entrevista, com o intuito de preservar a idoneidade do estudo.

Para a coleta dos dados foram utilizadas duas técnicas distintas de levantamento: questionário fechado enviado 
para a empresa brasileira de cachaça Sagatiba, com questões específicas à atuação da empresa no mercado internacional, e, questionário eletrônico com perguntas fechadas relacionadas ao consumo de bebidas e direcionado às pessoas domiciliadas no continente europeu, especificamente na Alemanha e Reino Unido.

Segundo Yin (2010) dentre as estratégias de pesquisa existentes, os estudos de caso tendem a ser o método mais utilizado quando se propõe questões do tipo "como" e "por que", quando o foco se encontra em acontecimentos menos contemporâneos inseridos na atualidade e, principalmente, quando o pesquisador tem pouco ou nenhum controle sobre os fatos. Dessa forma, o estudo de caso não é considerado nem um método de coleta de dados nem uma característica do planejamento em si, mas uma estratégia de pesquisa abrangente.

Uma vez que o objetivo deste estudo foi descrever como as estratégias de internacionalização influenciam a evolução de uma marca para o nível top of mind, a estratégia da pesquisa de estudo de caso se faz apropriada para o trabalho. O estudo de caso, então, foi desenvolvido combinando informações públicas da empresa e questionários de perguntas fechadas respondidos pela Sagatiba.

Considerando que o questionamento do estudo envolveu a marca top of mind e fez alusão à percepção dos clientes com relação à marca de um produto ou serviço, foi utilizado, conjuntamente com o estudo de caso, um questionário com perguntas fechadas direcionado à amostra pré-estabelecida no estudo.

O questionário aplicado para esse grupo da amostra contou com a técnica da Escala Likert que, segundo Aaker, Kumar e Day (2010), faz parte de uma gama de ferramentas de mensuração de atitude desenvolvidas para estimar amostras de crenças em relação ao objeto estudado e combinar tais respostas obtidas em forma de pontuação.

Aaker, Kumar e Day (2010) expuseram ainda que a Escala Likert avalia o grau de concordância ou não em relação ao encadeamento de afirmações elencadas ao objeto de pesquisa. É normalmente dividida em duas partes, uma para o item e outra para avaliação.

Na primeira divisão há uma afirmação a respeito de um determinado produto, atitude ou evento.

$\mathrm{Na}$ segunda, a avaliativa, encontrase uma lista de cinco categorias ordinais de resposta, iniciando-se de "improvável" até "fortemente favorável". Assim, torna-se possível obter-se um nível de concordância com relação aos temas e afirmações contidas no questionário.

Uma vez que o estudo pretendeu obter resposta de amostra presente em outro continente, o questionário com afirmações se revelou aplicável ao tipo de pesquisa proposta.

O Quadro 2 apresenta o conjunto de afirmações que o entrevistado respondeu na escala Likert acima descrita.

Quadro 2. Modelo de Questionário Enviado para Público Europeu

\begin{tabular}{|l|}
\hline AFIRMAÇÕES PARA PÚBLICO EUROPEU (VERSÃO PORTUGUES) \\
\hline 1. Dificilmente compro uma marca sem nunca ter ouvido falar dela \\
\hline 2. Mesmo sem conhecer o produto, uma boa propaganda chama minha atenção para a compra \\
\hline 3. A embalagem de um produto contribui para minha decisão de compra \\
\hline 4. A acessibilidade aos canais de venda do produto colabora para aquisição do mesmo \\
\hline 5. Prefiro marcas comercializadas em locais de alto padrão \\
\hline 6. Propagandas que vinculam a cultura do país de origem do produto tendem a ser mais atrativas \\
\hline 7. Marcas provindas de países com cultura exótica chamam minha atenção à compra \\
\hline 8. As marcas mais renomadas no mercado são minha opção número um \\
\hline 9. Estou disposto a pagar mais por um produto de marca renomada a uma marca alternativa \\
\hline 10. Não vejo problemas em comprar uma marca estrangeira nova no mercado \\
\hline
\end{tabular}

Fonte: Entrevistas realizadas pelos Autores 


\section{Análise e Tratamento dos Dados}

Os dados obtidos foram confrontados com o referencial teórico, com o propósito de estabelecer associações já conhecidas ou novas interações entre as variáveis, eventualmente não apontadas na literatura consultada.

Através da análise de conteúdo visou-se obter, via procedimentos sistemáticos, indicadores que permitissem a inferência de conhecimentos acerca de seu
Abrão Caro

Livia Rodrigues Silva

Marina Ramos Almeida conteúdo, conforme recomenda Bardin (2007).

Um pré-teste foi realizado com 35 entrevistados, todos residentes na cidade de São Paulo e com idade entre 20 e 30 anos. O resultado obtido com relação ao entendimento das perguntas foi satisfatório, não sendo necessárias correções. Foram então contatados 100 consumidores europeus, dos quais 50 responderam conforme dados da Tabela 1.

Tabela 1. Tabulação das respostas ao questionário de consumidores europeus

\begin{tabular}{|c|c|c|c|c|c|c|c|}
\hline \multirow{3}{*}{ Questão } & \multicolumn{6}{|c|}{ Respostas Escala Likert } & \multirow{3}{*}{ Total } \\
\hline & 1 & 2 & 3 & 4 & 5 & \multirow[b]{2}{*}{$\begin{array}{c}\text { Em } \\
\text { Branco }\end{array}$} & \\
\hline & Improvável & $\begin{array}{c}\text { Pouco } \\
\text { provável }\end{array}$ & Indiferente & Favorável & $\begin{array}{c}\text { Fortemente } \\
\text { Favorável }\end{array}$ & & \\
\hline 1 & 13 & 9 & 9 & 18 & 1 & 0 & 50 \\
\hline 2 & 5 & 11 & 9 & 22 & 3 & 0 & 50 \\
\hline 3 & 5 & 11 & 10 & 17 & 7 & 0 & 50 \\
\hline 4 & 1 & 3 & 10 & 28 & 8 & 0 & 50 \\
\hline 5 & 8 & 9 & 21 & 10 & 1 & 1 & 50 \\
\hline 6 & 4 & 16 & 14 & 11 & 5 & 0 & 50 \\
\hline 7 & 8 & 12 & 21 & 6 & 3 & 0 & 50 \\
\hline 8 & 8 & 17 & 8 & 14 & 2 & 1 & 50 \\
\hline 9 & 10 & 17 & 9 & 11 & 2 & 1 & 50 \\
\hline 10 & 2 & 3 & 8 & 27 & 9 & 1 & 50 \\
\hline
\end{tabular}

Fonte: Entrevistas realizadas pelos Autores

A análise da concentração de respostas permitiu deduzir-se que:

i. Consumidores dispostos a comprar produtos de empresas estrangeiras;

ii. Baixa sensibilidade a elementos do país de origem da marca, mas sensíveis a customizações de acordo com padrões locais;

iii. Decisão de compra passa por conhecimento prévio de uma marca ou uma estratégia de comunicação atrativa, além da disponibilidade e do correto posicionamento de mercado.

O estudo de caso da empresa Sagatiba mostrou que a sua estratégia de internacionalização considerou:

i. A combinação entre aspectos percebidos no mercado e características internas da empresa;

ii. O planejamento global e a adaptação da comunicação de acordo com cada mercado;

A atuação por meio de nichos de mercado para a obtenção da marca top of mind. 


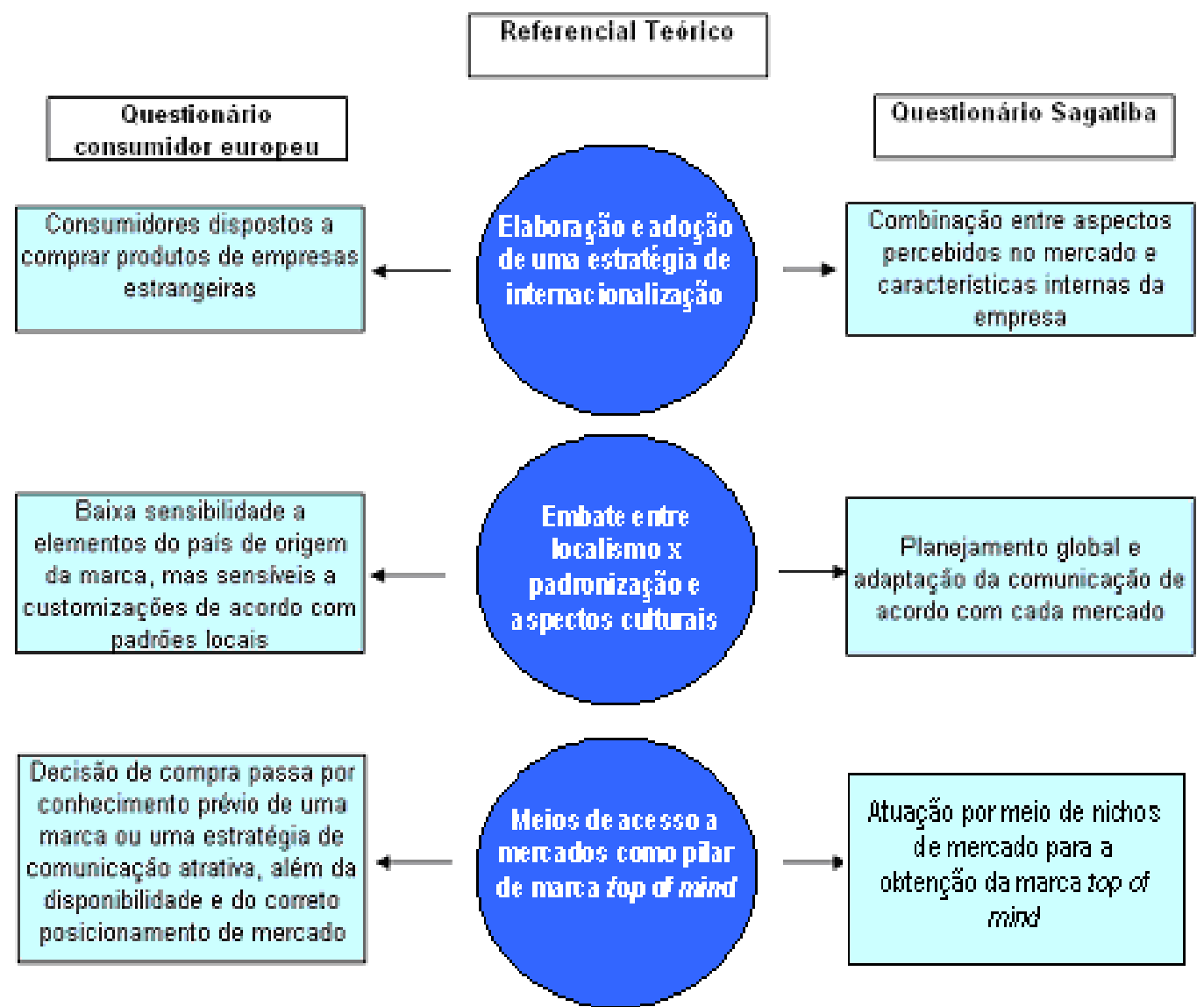

Figura 1. Cruzamento de dados - Referencial Teórico e dados coletados

Fonte: Pequisa realizada pelos Autores

A Figura 1 apresenta o cruzamento entre a percepção do consumidor europeu, com relação a novos entrantes, e as estratégias de internacionalização adotadas pela Sagatiba. No tronco da Figura 1 são relacionados os principais elementos teóricos acerca da construção de estratégias de internacionalização, à esquerda são mostrados os dados obtidos por meio da amostra de consumidores europeus e à direita os dados do estudo de caso da Sagatiba.

O cruzamento dos dados qualitativos permite uma visão panorâmica e clara do conteúdo obtido neste estudo e permite uma análise da relação entre estratégias de internacionalização e marca top of mind.

\section{Conclusões}

Através dos dados obtidos, e considerando-se o caráter descritivo e qualitativo do estudo, pode-se afirmar que a fundamentação teórica se confirmou na prática. Alguns pontos explorados nos questionários se destacaram: elaboração e escolha de estratégias em função de características de mercado e condições internas da empresa; observação dos aspectos culturais nos mercados internacionais e do próprio país de origem do produto; embate entre padronização e localismo; atuação em nichos de mercado; utilização estratégica dos meios de acesso ao comércio internacional (exportações simples, alianças, joint ventures, entre outros), foram corroborados na prática.

Importantes elementos sobre marcas e a condição top of mind também foram avaliados e não convergiram totalmente com a teoria. O questionário apresentado aos consumidores europeus foi bastante elucidativo com relação às marcas top of mind, apontando que, diferentemente do exposto por Aaker (1998), a 
Francisco Américo Cassano

Carlos Eduardo G. Saraiva Jr.

Rafael Martins Prado Oliveira

marca top of mind em si não representa vantagem competitiva, mas, sim, o processo que uma organização conduz para elevar sua marca a esse nível de reconhecimento.

Observando-se o cruzamento dos instrumentos de coleta de dados com o referencial teórico (Figura 1), foi possível constatar-se a influência das estratégias de internacionalização sobre a marca top of mind. Tal situação ficou clara pela análise da percepção dos consumidores europeus sobre novos entrantes não representar, por si só, diferenciação na decisão de compra, mas sim aspectos de comunicação, disponibilidade de produto e posicionamento de mercado, complementado pela Sagatiba com a qualidade do produto e a degustação como tática de vendas.

Nota-se que os fatores determinantes para o sucesso da marca são da esfera da estratégia de internacionalização, ou seja, das escolhas realizadas pela organização para atuar no comércio internacional. É pelo desdobramento da estratégia de internacionalização que se dará o desempenho da marca no exterior, podendo-se assumir a hipótese de que o modo como uma empresa se internacionaliza tem reflexos sobre a percepção de sua marca frente aos consumidores.

Os dados também fornecem subsídios qualitativos suficientes para se responder satisfatoriamente o problema de pesquisa do estudo, visto a demonstração de como a estratégia de internacionalização de uma empresa pode contribuir para que sua marca seja top of mind nos mercados de atuação, observando critérios como aspectos culturais, percepções do consumidor, atuação em nichos de mercado, entre outros. Também foi possível descrever-se os mecanismos a serem adotados pelas empresas que buscam uma internacionalização com foco na obtenção de marcas top of mind e atingir o objetivo geral do estudo de descrever como as estratégias de internacionalização podem ajudar uma organização a firmar sua(s)
Abrão Caro

Livia Rodrigues Silva

Marina Ramos Almeida

marca(s) como top of mind nos mercados de atuação.

As limitações do estudo restringemse ao fato de se utilizar apenas uma empresa/marca como referência e, por esse fato, não poder haver generalização para o setor de bebidas. Como contribuição, sugere-se que em novos estudos sejam analisadas mais empresas desse setor, permitindo uma visão mais ampla sobre o tema.

\section{Referências}

AAKER, D. A. Marcas: Brand Equity gerenciando o valor da marca. São Paulo: Negócio, 1998.

AAKER, D. A.; JOACHIMSTHALER, E. Como construir marcas líderes. São Paulo: Futura, 2007.

AAKER, D. A.; KUMAR, V.; DAY, G. S. Pesquisa de marketing. 2. ed. São Paulo: Atlas, 2010.

ANSOFF, H. I.; MCDONNELL, E. J. Implantando a administração estratégica. São Paulo: Atlas, 2009.

ALMEIDA, A. Internacionalização de empresas brasileiras: perspectivas e riscos. Rio de Janeiro: Elsevier, 2007.

BARDIN, L. Análise de Conteúdo. 4. ed. Lisboa: Edições 70, 2007.

BARTLETT, C. A.; GHOSHAL, S. Gerenciando empresas no exterior - a solução transnacional. São Paulo: Makron Books, 1992.

DIB, L. A.; ROCHA, A. D. Internacionalização precoce versus internacionalização gradual: um estudo sobre Born Globals na indústria brasileira de software. Anais do XXXII Encontro da Associação Nacional de Pós-Graduação e Pesquisa em Administração - ENANPAD. Rio de Janeiro, 2008.

EDVINSSON, L.; MALONE, M. S. Capital Intelectual. São Paulo: Makron Books, 
1998.

GHEMAWAT, P. Redefinindo Estratégia

Global. Porto Alegre: Bookman, 2008.

A Estratégia e o Cenário

dos Negócios. 2. ed. Porto Alegre: Bookman, 2007.

GRAYSON, D.; HODGES, A. Compromisso social e gestão empresarial. São Paulo: Publifolha, 2002.

HENDERSON, B. D. As origens da estratégia. In: PORTER, M. E.; MONTGOMERY C. A. Estratégia: A busca da vantagem competitiva. São Paulo, Campus, 1998.

HITT, M. A.; IRELAND, R. D.; HOSKISSON, R. E. Administração estratégica: competitividade e globalização. 2. ed. São Paulo: Thomson Learning: Cengage Learning, 2008.

HOUAISS, A. Dicionário Houaiss da Língua Portuguesa. São Paulo: Objetiva, 2006.

JOHANSON, J.; VAHLNE, J. The internationalization process of the firm: A model of knowledge development and increased market commitments. Journal of International Business Studies, v. 8, n. 1, p. 23-32, 1977.

JOHNSON, G.; SCHOLES, K.; WHITTINGTON, R. Explorando a Estratégia Corporativa. Porto Alegre: Bookman, 2007.

KOTLER, Philip. Administração de marketing: a edição do novo milênio. 10. ed. São Paulo: Pearson Prentice Hall, 2009.

LORGA, S. C. Internacionalização e rede de empresas. São Paulo: Verbo, 2003.

MINTZBERG, H. O processo da estratégia: conceitos, contextos e casos selecionados. 4. ed. Porto Alegre: Bookman, 2006.

NUMMELA, N. SAARENKETO, S. PUUMALAINEN, K. A Global Mindset - A Prerequisite for Successful Interna- tionalization? Canadian Journal of Administrative Sciences, 21(1), 51-64, 2004.

PERLMUTTER, H. V. The Tortuous Evolution of the Multinational Corporation. Columbia Journal of World Business, jan-feb 1969, 9-18.

PIRES, N. C. M.; ARANTES, E. C.; SILVA, W. V.; KATO, H. T. Diferenças e Semelhanças nos Métodos de Amostragem de Pesquisas Top of Mind: Um Estudo Comparativo. São Paulo, Revista Brasileira de Gestão de Negócios, Vol. 8, n.22, p. 37-45, 2006. Disponível em http://200.169.97.104/seer/index.php/RBG N/article/view/67/61. Acesso: em 10 ago. 2012.

PORTER, M. E. Como as forças competitivas moldam a estratégia. Revista Harvard Business Review, marçoabril 1979, p. 127-136.

PORTER, M. E.; MONTGOMERY, C. A. Estratégia: A busca da vantagem competitiva. 2. ed. São Paulo, Campus, 1998.

SAGATIBA BRASIL S/A. Quem somos. Disponível em http://www.sagatiba.com.br /quem-somos/. Acesso em 25 mar. 2013.

STEWART, T. A. Capital intelectual: a nova vantagem competitiva das empresas. 12.ed. Rio de Janeiro: Elsevier, 2004.

YIN, Robert K. Estudo de caso: planejamento e métodos. 4. ed. Porto Alegre: Bookman, 2010. 


\section{Apêndices}

\section{Apêndice 1. Questionário para público europeu (versão português)}

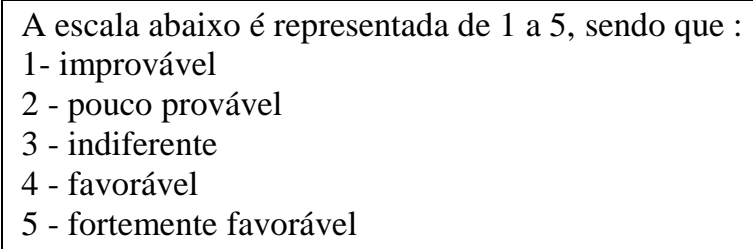

1-) Eu costumo comprar marcas novas no mercado mesmo que nunca tenha ouvido falar da mesma.
1 -
2-
$3-$
$4-$
$5-$

2-) Mesmo sem conhecer o produto, uma boa propaganda chama minha atenção para a compra.

$$
1 \text { - 2- 3- } \quad 4-\quad 5 \text { - }
$$

3-) A embalagem de um produto contribui para a minha decisão de compra.
1 -
2-
3 -
4-
$5-$

4-) A acessibilidade aos canais de venda do produto colabora para a aquisição do mesmo.

$$
1 \text { - 2- } \quad 3 \text { - } \quad 4-\quad 5 \text { - }
$$

5-) Prefiro marcas comercializadas em locais de alto padrão.
1 -
2-
3 -
4-
$5-$

6-) Propagandas que vinculam a cultura do país de origem do produto tendem a ser mais atrativas

$$
1 \text { - 2- 3- } \quad 4-\quad 5 \text { - }
$$

7-) Marcas provindas de países com cultura exótica chamam minha atenção a compra.
1 -
2-
3-
4-
$5-$

8-) As marcas mais renomadas no mercado são minha opção número um.
1 -
2-
3 -
4-
5-

9-) Estou disposto a pagar mais por um produto de marcada renomada à uma marca alternativa.
1 -
2-
3 -
4-
5 -

10-) Não vejo problemas em comprar uma marca estrangeira nova no mercado.

1 - 2- 3 - 4 -

\section{Apêndice 2. Questionário Sagatiba}

1. Por que a Sagatiba decidiu nascer global, ou seja, desde a fundação da empresa atuar no mercado externo?

2. Como se deu o processo de escolha pelos países de atuação (UK, USA, Alemanha, Noruega, Suíça, Portugal, Grécia, Holanda, Itália, etc.)? Foram utilizados métodos de análise de comportamento de consumo, cultura, informações demográficas, entre outros (ex: SWOT)?

3. Como, internamente, a empresa se adaptou para atuação global (ex: perfil global de equipes, escritórios em vários países, hierarquias globalizada, etc.)?

4. Atuando em diversos mercados, quais foram as principais preocupações com relação a aspectos culturais? $\mathrm{O}$ que a Sagatiba fez para lidar com essa questão de vender em culturas diferentes?

5. Diferentes mercados costumam demandar certo grau de customização dos produtos. Como a Sagatiba lidou com isso? (ex: necessidade de adaptar fórmulas para gostos de paladar, questão de cachaça = rum nos EUA, vários idiomas no rótulo, diferentes tipos de cachaça, a linha nobre, mini garrafas, etc.).

6. Existe um perfil de consumidor Sagatiba? Um nicho de mercado específico que a empresa pretende atingir dentro dos países de atuação?

7. A Sagatiba possui forte apelo à brasilidade e utiliza esse fator com maestria em suas campanhas. Quais foram as precauções tomadas para evitar que os consumidores não se identificassem com os símbolos do Brasil? (ex: um nórdico não se identificando com apelos tropicais)

8. Existe predileção por algum meio de distribuição dos produtos (exportações simples, joint ventures, alianças, franquias, escritórios próprios, etc.) que facilite e ajude no processo de interação com o consumidor final?

9. A marca de um produto representa sua identidade e transmite importantes mensagens para o público. O nome Sagatiba (Saga - busca lendária e Tiba - abundância), o S que lembra o símbolo do infinito, etc. Toda essa preocupação com a marca era apenas para despertar um interesse inicial dos consumidores ou já fazia parte de um processo de associar Sagatiba com cachaça e elevar a marca para top of mind (como Gilette, Coca-Cola, Omo, etc.)? Esse reconhecimento da marca pelos consumidores é uma vantagem competitiva para Sagatiba?

10. O documentário da BBC de Londres sobre as campanhas da Sagatiba com a Saatchi \& Saatchi comenta sobre os altos investimentos da empresa nas ações de marketing (eventos, campanhas comerciais, etc.). Essa 
busca por ser top of mind, ou seja, referência no mercado de cachaça é o que garantirá a perpetuidade do negócio e que também facilitará a entrada em novos países?

11. Vocês já realizaram alguma pesquisa para medir a responsividade dos clientes com relação a marca Sagatiba? Se sim, poderiam se posicionar com relação ao desempenho da marca?

12. Realizou-se uma pesquisa com cerca de 100 entrevistados e obteve-se respostas de 50. O público era formado por europeus. Poderiam comentar os comportamentos identificados na pesquisa, tendo em vista o posicionamento da marca Sagatiba nesses mercados?:

- Dificilmente os europeus compram uma marca sem nunca ter ouvido falar dela

- Mesmo não conhecendo uma marca, um bom anúncio chama atenção dos consumidores para realizar uma compra teste

- O design do produto é um importante decisor de compra

- Preferência por produtos comercializados em locais de fácil acesso

- Não há preferência por produtos vendidos em pontos de alto padrão (luxo)

- Explorar elementos do país de origem nas campanhas não costuma tornar os produtos mais atrativos

- Os consumidores não têm preferência por produtos de países exóticos

- Não estão dispostos a pagar mais simplesmente pelo produto ser de uma marca famosa (pagar mais pela etiqueta)

- Os consumidores não têm problemas em comprar novas marcas estrangeiras 